\title{
PRÁTICA SOCIAL, HIPNOSE E DOR CRÔNICA: ALTERNATIVAS DE COMPREENSÃO ${ }^{1}$
}

\author{
Mauricio da Silva Neubern
}

\begin{abstract}
RESUMO. O presente trabalho propõe, pela noção de prática social, uma alternativa de compreensão da relação entre hipnose e dor crônica. Partindo de uma crítica às pesquisas contemporâneas, são investigadas três importantes zonas de sentido dessa aplicação da hipnose: sua dimensão relacional; a fabricação do fenômeno hipnótico e o conto de histórias. Semelhantes zonas remetem à subjetividade presente em tais processos sociais, uma vez que implica a materialidade das relações, a construção de papéis, a diversidade de expressões do transe e a multiplicidade de sugestões presentes nos contos. Na conclusão, enfatiza-se a importância de que uma compreensão clínica e qualitativa das relações entre hipnose e dores crônicas subsidie as pesquisas com informações pertinentes dessa pratica social, para que os pesquisadores não descaracterizem com metodologias distanciadas de suas características.
\end{abstract}

Palavras-chave: Hipnose; dor crônica; prática social.

\section{SOCIAL PRACTICE, HYPNOSIS, AND CHRONIC PAIN: ALTERNATIVES FOR COMPREHENSION}

\begin{abstract}
This paper proposes an alternative to understand the relationship between hypnosis and chronic pain based on the notion of social practice. Beginning with a critique of contemporary research, this study investigates three important sense zones of this hypnosis application: its relational dimension, the fabrication of the hypnotic phenomenon, and telling stories. Similar zones refer to the subjectivity present in such social processes, since it implies the material aspect of relationships, the construction of roles, the diversity of trance expressions, and the multiplicity of suggestions in stories. The conclusion emphasized the importance of clinical and qualitative understanding of the relationships between hypnosis and chronic pain in supporting research with information pertinent to this social practice, so that researchers do not mischaracterize it with methodologies disconnected from its characteristics.
\end{abstract}

Key words: Hypnosis; chronic pain; social practice.

\section{PRÁCTICA SOCIAL, HIPNOSIS Y DOLOR CRÓNICO: ALTERNATIVAS DE COMPRENSIÓN}

RESUMEN. El presente trabajo propone, a partir de la noción de práctica social, una alternativa de comprensión de la relación entre hipnosis y dolor crónico, partiendo de una crítica a las investigaciones contemporáneas. Investiga tres importantes zonas de sentido de esta aplicación de la hipnosis: su dimensión relacional; la fabricación del fenómeno hipnótico y el cuento de historias. Semejantes zonas remiten a la subjetividad presente en tales procesos sociales, una vez que implica la materialidad de las relaciones, la construcción de papeles, la diversidad de expresiones del trance y la multiplicidad de sugerencias presentes en los cuentos. En la conclusión se enfatiza la importancia de que una comprensión clínica y cualitativa de las relaciones entre hipnosis y dolores crónicos sirva de apoyo a las investigaciones con informaciones pertinentes de esta práctica social, para que los investigadores no quiten el carácter con metodologías distanciadas de sus características.

Palabras-clave: Hipnosis; dolor crónico; práctica social.

Apoio e Financiamento: Departamento de Pós-Graduação e Pesquisa - UnB.

Doutor em Psicologia, professor adjunto do Departamento de Psicologia Clínica - Instituto de Psicologia, Universidade de Brasília (UnB). Fundador do Instituto Milton H. Erickson de Brasília. 
O uso da hipnose como intervenção clínica para aliviar dores decorrentes de diversos tipos de problemas não é recente (Neubern, 2009c) e possui sua eficácia comprovada por ampla variedade de pesquisas contemporâneas (Jensen \& Patterson, 2006). Algumas enfatizam suas aplicações quanto a problemas específicos de origem oncológica (Liossi, 2006), dificuldades sexuais (Kandiba \& Biniki, 2003) e fibromialgia (Nogueira, Lauretti \& Costa, 2005), outras dão ênfase a questões referentes a certos grupos de pessoas (Jensen \& Patterson, 2006), enquanto outras ainda se concentram sobre temas como a hipnotizabilidade (Carli, Huber \& Santarcangelo, 2008) e modelos teóricos específicos (Turk, Swanson \& Tunks, 2008). Tal como levantado em certos estudos (King, Nash, Spiegel \& Jobson, 2001), o conhecimento dessa literatura pode ser de grande valia por permitir ao terapeuta um conhecimento geral e estatístico referente a certos procedimentos, grupos populacionais específicos e características particulares de determinados problemas ou doenças que se encontram ligados às experiências de dores de seus pacientes. Podem apontar para tendências importantes na abordagem de casos particulares, destacando possíveis condições a serem consideradas ou ainda cuidados e precauções a serem tomados.

No entanto, possivelmente pelo caráter nomotético dessas pesquisas, não há uma consideração mais profunda sobre a forma como a hipnose é praticada nas situações estudadas, de maneira que todo um campo de investigação fundamental para a compreensão do processo hipnótico acaba por ser menosprezado (Neubern, 2009b; 2009c). A ênfase sobre questões como a eficácia da hipnose parece desviar as atenções para os possíveis resultados dessa prática, em detrimento de suas formas e processos de produção da mudança mobilizadas na experiência de dor dos sujeitos. Assim, da mesma forma que tais estudos desconsideram as propostas diversificadas de hipnose, também não conferem importância a aspectos qualitativos centrais de sua clínica, como os processos subjetivos da relação terapêutica (Erickson, 1983), o uso da linguagem (Melchior, 1998; Martins \& Batista, 2002), os processos simbólicos configurados na dor e na relação terapêutica (Neubern, 2009b), o uso dos fenômenos hipnóticos (Edgette \& Edgette, 1995), dentre outros. Desse modo, embora possam constatar a eficácia da hipnose como instrumento terapêutico, deixam várias lacunas sobre sua forma de funcionar, o que remete a aspectos que ocupam uma importância central do trabalho com pacientes acometidos por dores crônicas de diferentes naturezas.

Embora semelhantes perspectivas retomem a hipnose como um tema digno da pesquisa científica, elas parecem trazer consequências pouco construtivas para sua compreensão, principalmente por enfatizá-la como um instrumento técnico e não abrir espaço para as dimensões de subjetividade que nela tomam parte (Erickson, 1983; Neubern, 2009b). Por não oferecerem visibilidade ao jogo interativo e simbólico que se desenrola na relação terapêutica, não fica claro o papel que o terapeuta possui no processo, quais condições de contexto precisam estar presentes para que seja terapêutico e o que cabe ao paciente assumir para seu próprio processo de mudança. Assim, tais estudos podem reforçar, mesmo sem a intenção de seus autores, uma série de preconceitos que sempre prejudicaram a difusão da hipnose, como o de um poder unilateral do terapeuta, a redução a um mero processo instrumental e a passividade do paciente, cuja participação seria limitada a emitir respostas aos comandos das sugestões vindas de outro (Neubern, 2009a). Não seria exagero considerar que, por tais estudos, a dor crônica fosse concebida como um objeto isolado da vivência do sujeito, a ser aliviada de forma instrumental pela hipnose, cuja maestria caberia a um profissional treinado e não a um processo relacional em que o paciente possuísse também uma participação decisiva.

No entanto, concebe-se que a hipnose aplicada a pessoas que vivenciam dores crônicas está muito mais identificada a uma relação comum entre pessoas, a como se dirigem umas às outras, aos modos pelos quais se movem na coreografia da interação, ao que pensam e sentem nesse processo e aos papéis que nele desempenham influenciados por uma cultura. Isso permite considerar que o estudo da hipnose, ao invés de buscar reduzi-la a um objeto inanimado de laboratório, deve buscar contemplá-la como prática social (Bourdieu, 2000), ou seja, uma prática que se inscreve numa tradição, que envolve crenças e movimentos corporais técnicos, atualizados naquele momento por seus protagonistas (ou seja, um habitus), e que ocorre num interjogo sociocultural contextualizado e produtor de sentidos subjetivos. Tal perspectiva apresenta-se promissora por possibilitar a abordagem, em larga medida, de importantes momentos do processo hipnótico raramente contemplados nas pesquisas contemporâneas, como a relação do terapeuta com sua tradição prática e técnica, a qualidade relacional que se estabelece com o paciente e a produção subjetiva ${ }^{2}$ (Gonzalez Rey, 2007) deste que, por esse processo, torna-se capaz de modificar sua experiência de dor crônica. A

\footnotetext{
Por subjetividade compreende-se aqui a constituição psíquica dos sujeitos, cuja materialidade, tecida nos interjogos sócio-culturais em que o sujeito se insere, organiza-se numa lógica configuracional gerando emoções, significados e sentidos subjetivos (Gonzalez Rey, 2007).
} 
reconfiguração de crenças, sentidos e emoções, a mudança de perspectivas de vida e formas de relação consigo e com o outro, como a emergência de determinados fenômenos hipnóticos, em suma, processos que coincidem com a modificação da dor do sujeito (Neubern, 2009b; 2009c) ganham maior visibilidade e enriquecem a compreensão do uso da hipnose na dor crônica de maneira que a hipnose passa a ir além de simples jogo de sugestões e respostas para se situar num processo relacional inserido num determinado contexto.

Desse modo, o objetivo do presente trabalho é o de oferecer, por meio da concepção da hipnose como prática social (Bourdieu, 2000), uma alternativa de compreensão do processo hipnótico para pessoas portadoras de dores crônicas que proporcione maior visibilidade à complexidade de procedimentos técnicos utilizados e a seu potencial gerador de produção subjetiva. Assim, ao mesmo tempo em que se busca um aprofundamento da discussão sobre o uso das técnicas, num dado contexto relacional, abre-se uma perspectiva para abarcar o potencial de reconfiguração de experiências desses usos junto a pacientes com dores crônicas. Nesse sentido, também serão destacados possíveis caminhos para a construção da pesquisa, ressaltando exigências, características e critérios desse campo que raramente são abordados nas pesquisas contemporâneas. Para tanto, serão enfocadas três zonas de sentido ${ }^{3}$ distintas (Gonzalez Rey, 2005), que possuem especial importância na tradição clínica da hipnose (Erickson, 1983; Erickson \& Rossi, 1980): a relação entre pessoas; a fabricação do fenômeno hipnótico; e o conto de histórias. No primeiro tópico, a relação entre pessoas será destacada como determinadas crenças e ações presentes no uso da técnica que promovem um processo relacional específico e favorece que o paciente assuma o papel de sujeito. Já no tocante à fabricação do fenômeno hipnótico, será ressaltado como determinadas ações, crenças e usos de linguagem do terapeuta remetem a uma dimensão além da intencionalidade da pessoa - o inconsciente - em que são produzidos fenômenos que apresentam considerável poder de transformação da experiência do sujeito. E, por fim, no que se refere ao conto de histórias, será abordado como a construção de contos efetivada pelo terapeuta, pela crença de uma semelhança simbólica com os temas vividos pelo

3 Zonas de sentido são espaços da realidade que se tornam inteligíveis às construções do pensamento de um pesquisador (Gonzalez Rey, 2005). Essa inteligibilidade implica em criação de conceitos e visibilidade desses espaços na construção de uma pesquisa. sujeito, pode oferecer novas e importantes perspectivas para a reconfiguração de sua experiência.

\section{UMA RELAÇÃO ENTRE PESSOAS}

Um dos princípios ou crenças fundamentais para o trabalho hipnótico com dores crônicas, na perspectiva aqui adotada (Erickson \& Rossi, 1980), é que esta seja considerada enquanto uma experiência subjetiva da pessoa, a despeito de possuir ou não uma causa orgânica identificada. A dor como processo vivido não remete a um corpo inanimado e objetivo que fornece respostas mensuráveis, mas à experiência de uma pessoa que se constitui em processos emocionais e simbólicos complexos que se produzem em seu mundo pelos seus diferentes momentos de inserção social (Erickson, 1983; Neubern, 2009b). Assim, embora o terapeuta possa adquirir informações importantes a partir de técnicas objetivas de avaliação, é necessário que ele se disponha a considerar o que essa dor significa para o sujeito e que perspectivas ela cria em sua vida. A revolta pela ruptura de um projeto de vida, o sentimento de fracasso pela impossibilidade de cumprir um papel familiar, a sensação de abandono pelo isolamento ou restrição de convívio social, a vergonha pela perda de uma profissão e de poderio econômico, a inconformação pelas alterações físicas sofridas na autoimagem são exemplos comuns que se enraízam em sua experiência de corpo, em sua relação consigo mesmo e no contato com os outros (MerleauPonty, 2008). Daí a condição necessária de que o terapeuta, na hipnose, considere que diante de si há, antes de tudo, uma pessoa e não meramente um corpo objetivado e que a dor que a acomete consiste em processos subjetivos complexos de seu mundo de experiências vividas que podem fazer referência a seu próprio existir. Semelhante atitude da parte do terapeuta remete a duas questões fundamentais que se articulam intrinsecamente.

Primeiramente, essa disposição quanto ao outro implica na possibilidade da construção de um legítimo contrato terapêutico, ou seja, na constituição de um vínculo que se cria entre ambos e na entrega pessoal de cada um ao processo hipnoterápico. Se, por um lado, o contrato terapêutico precisa contar com a formação teórica e técnica e com a disposição pessoal de acolhimento do terapeuta, por outro, exige que o paciente sinta que está na condição de sujeito do próprio processo (Neubern, 2010). Isto porque, embora haja considerável importância no tocante à qualidade técnica e emocional do terapeuta, é a participação ativa do sujeito no processo que é decisiva para a alteração da experiência de dor 
crônica, como se dá nas reconfigurações da experiência, nas produções de sentidos e na fabricação de determinados fenômenos hipnóticos. Dito de outro modo, é necessário que a experiência de mudança aconteça enquanto uma apropriação do sujeito, isto é, com um sentido de originalidade de algo que é seu, porque envolveu sua participação, a evocação de seus recursos, de seu trabalho interno e a mobilização de si mesmo como sujeito no processo terapêutico. Assim, ao mesmo tempo em que esse contrato o toca emocionalmente, posto que encontra eco diante de seu mundo de experiências e aprendizados, o paciente se sente participante do processo terapêutico que, antes estranho e externo a ele, passa a ganhar novas cores em seu mundo, por produzir sentidos subjetivos e emocionalidade capazes de fazer frente a suas demandas.

Desse modo, uma vez que o paciente se concebe como sujeito na relação terapêutica ou está em vias de assumir essa condição, o trabalho com eventuais bloqueios e resistências, comuns em pacientes com dores crônicas e recorrentes, torna-se viável. A aversão a procedimentos invasivos e dolorosos, a dificuldade de aceitação de sua situação médica, a sabotagem quanto a certos procedimentos e a possibilidade da morte são alguns dos exemplos de problemas que comumente alimentam narrativas sem perspectiva e esperança e precisam ser considerados como parte da situação clínica trazida pelo sujeito (Erickson, 1983). Logo, se ele encontra um espaço onde se escuta respeitosamente a razão de ser de suas posturas e histórias, o paciente tende a se colocar disponível para o trabalho com o terapeuta e seus possíveis questionamentos. Nesse sentido, a hipnose pode ser de grande importância, não só por permitir modificações iniciais e significativas na experiência de dor, mas também por proporcionar espaços imaginários nos quais o paciente revise sua trajetória de vida e considere elementos relevantes de sua história que até então pareciam estar encobertos pelo sofrimento presente (Erickson, 1966). Com novas peças de um complexo quebra cabeças sendo acrescentadas a suas reflexões, é possível que ele consiga pensar de outra forma sua situação atual, sua relação com o tratamento e suas perspectivas de futuro.

Em segundo lugar, ao considerar o paciente em sua condição humana, o terapeuta desenvolve uma forma empática de acessar seu mundo de experiência que pode envolver duas dimensões. A primeira delas, profundamente marcada pela intensa materialidade da relação (Bachelard, 2007), refere-se a processos nãoverbais da comunicação (Csordas, 2002; Roustang, 2006). A troca de olhares, a coreografia mútua entre os movimentos dos membros e do corpo, a retórica na forma de entonar a voz ao falar, o jogo das expressões corporais, musculares e faciais remetem a todo um espaço vivido que marca significativamente o corpo dos protagonistas, que frequentemente não percebem como essa força material da relação os influencia. Nesse sentido, é curioso notar como essa dimensão não-verbal pode produzir vivências de materialidade que são de grande importância para a clínica da dor: o contrato terapêutico costuma ser associado a uma sensação de conforto e segurança; o alívio, geralmente é relacionado a uma sensação de leveza ou saída da pressão de um grande peso; e a eficácia comumente aparece ligada à sensação de movimento, de saída de uma situação paralisante. Em outras palavras, a relação terapêutica estabelecida possui para os sujeitos uma qualidade material (Bachelard, 2007), mesmo sem contato físico, que influi diretamente sobre a dor, podendo trazer a sensação de massageá-la, dissolvê-la, escorrê-la, espalhá-la, enfim, modificá-la de forma eficaz.

Já a atenção com o uso da linguagem e expressões metafóricas do paciente, por outro lado, também é muito relevante para acessar essa experiência, pois, de alguma forma, tais práticas se referem a processos simbólicos profundos (Lakoff \& Johnson, 2003) que sintetizam com pertinência como essa dor é vivenciada. É assim que expressões como "meu mundo desabou”, "estou no inferno", "galeria de horrores", "máquina de tortura", "carne dilacerada", "frango desossado" remetem de modo muito relevante à experiência do sujeito, quando consideradas em seu próprio cenário subjetivo, e precisam ser conhecidas em sua pertinência tanto para uma compreensão e acolhimento mais profundos, como para a construção de diretrizes para o tratamento hipnótico (Erickson \& Rossi, 1979). As metáforas remetem a processos inconscientes profundos que de alguma forma sintetizam o momento da experiência do paciente e simbolizam, como numa espécie de enredo teatral, os personagens e elementos que compõem seu drama pessoal. Assim, o "frango desossado", relatado por uma paciente muito católica e acometida por grave artrose, parecia se referir, não só à terrível sensação de ter a carne separada dos ossos, mas também ao preparo de uma carne a ser comida pelos outros, o que era análogo ao tipo de papel familiar que lhe cabia cumprir, no qual ela sempre deveria se sacrificar para o benefício dos demais.

Logo, tanto a materialidade nessa relação empática, quanto o uso da linguagem aí presente podem conduzir o terapeuta à dimensão inconsciente da subjetividade, que embora seja perpassada por processos psíquicos automáticos, também é profundamente marcada pela constituição de sentidos 
subjetivos $^{4}$ (Gonzalez Rey, 2007). Mesmo sendo plásticos e podendo envolver emoções e significados contraditórios, os sentidos subjetivos passam a se constituir como referências dominantes no mundo do sujeito que podem favorecer, sem que ele se dê conta, determinadas posturas frente a suas dores, a seu tratamento, a si mesmo, às outras pessoas e a seu porvir (Neubern, 2009b). Cria-se, no inconsciente, uma espécie de rede simbólica formada por sentidos subjetivos diversos que pautam suas diretrizes, movimentos e disposições que poderão se situar como referências centrais do mundo de experiência do sujeito de maneira decisiva quanto a seu problema. No entanto, embora semelhante perspectiva pareça sugerir uma visão determinista, os sentidos devem ser concebidos como um conjunto de disposições que poderão ou não se concretizar nas ações do sujeito. Isto porque, além da plasticidade inerente à sua constituição, que pode se modificar no tempo e na dialética com o mundo social, o sujeito possui a possibilidade da escolha, mesmo em termos inconscientes (Erickson \& Rossi, 1980; Frankl, 2007).

Desse modo, seguindo-se à longa tradição da clínica da hipnose (Neubern, 2009c), torna-se possível a concepção de uma dimensão pessoal do inconsciente (um "eu” inconsciente), uma vez que o inconsciente, além dos processos psíquicos automáticos que o constituem, também denota uma dimensão personalizada da subjetividade com inteligência, emocionalidade e potencial de escolha. Isso permite considerar que, quando o terapeuta se endereça ao inconsciente de alguém, ele o faz dirigindo-se a uma dimensão mais profunda desta pessoa e não a uma máquina formada por dispositivos mecânicos, deterministas e impessoais. Por tal razão, é necessário que o terapeuta consiga se endereçar de forma eficiente a essa dimensão profunda, mas pessoal, tanto para a efetivação do contrato terapêutico, como para acionar suas possibilidades de criação e escolha que podem modificar significativamente as configurações da experiência de dor crônica do paciente. É nesse sentido que a hipnose não pode ser concebida como uma relação instrumental de controle e domínio, mas como um convite a uma relação humana que evoca dimensões mais profundas da subjetividade do

\footnotetext{
4 Os sentidos subjetivos, produzidos na dialética do sujeito com seu mundo social, são qualidades dominantes de processos sistêmicos da subjetividade - as configurações que integram dimensões emocionais e simbólicas de suas experiências subjetivas. Possuem a capacidade de organizar e influenciar a produção de emoções, significados, referências e percepções do sujeito, como também de influir em suas atitudes diante das diferentes facetas da experiência por ele vivida.
}

paciente ricas em possibilidades que ele mesmo parece desconhecer.

A forma desse endereçar-se ao outro em sua dimensão inconsciente não se restringe a aplicações técnicas, mas envolve também a pessoa do terapeuta que, a partir de sua própria vivência e reflexão, pode criar papéis que sejam pertinentes para momentos e necessidades específicos dessa relação (Zeig \& Geary, 2000). Como está integrado numa relação estreita e material com seu paciente, ele consegue perceber seus processos subjetivos singulares, mas também notar em si mesmo os sentimentos, impressões e ideias que esse contato evoca. Desse modo, ele constrói um papel dramático, que esteja coerente com seu mundo interno, de maneira semelhante ao que ocorre no teatro (Stanislawski, 2006) e que seja pertinente com as necessidades que emergem na relação terapêutica. É assim que, em certas situações, o terapeuta assume uma postura maternal, enquanto noutras há a necessidade do confronto; algumas necessitam de uma figura permissiva, ao passo que outras serão beneficiadas com uma postura de autoridade técnica e pedagógica; há pacientes que são beneficiados quando o terapeuta assume papel de cúmplice ou companheiro, como há aqueles que precisam de alguém que funcione como um professor ou guia.

Tais perspectivas levam a conceber que a técnica hipnótica, no que concerne ao relacional, abarca um habitus complexo e rico, uma vez que se encontra integrada a crenças, concepções teóricas, formas de ação, como pelo uso da linguagem, do corpo, da voz e pela construção de um papel dramático. No entanto, longe de se constituir como instrumento de uso unilateral, essa riqueza prática acaba caracterizando-se como um processo humano por excelência, não só por favorecer a produção de mudanças em processos subjetivos, mas principalmente por proporcionar a emergência, junto ao paciente, da condição de sujeito - condição fundamental para que o paciente assuma uma postura ativa e distinta diante das dores que o acometem. É essa condição que cria o espaço para que ele saia duma postura vitimizada e passiva para poder explorar seus próprios potenciais e atuar com outras perspectivas e atitudes, buscando novos caminhos para sua situação. É ela quem proporciona visibilidade para que as vozes que brotam de sua experiência se tornem visíveis para ele e os outros envolvidos, de maneira a atuar decisivamente no processo, dialogando, negociando e até confrontando a voz do saber oficial, respaldado pelas ciências médica, antes tida como a única possível. Em suma, é tornando-se sujeito que o paciente se torna autor de sua própria história. 


\section{A FABRICAÇÃO DOS FENÔMENOS HIPNÓTICOS}

Essa evocação de uma dimensão mais profunda da subjetividade da pessoa, o seu eu inconsciente, remete, na pauta da relação terapêutica, à visibilidade e utilização dos fenômenos hipnóticos que possuem importância nada desprezível na psicoterapia de dores crônicas (Erickson, 1983). Eles derivam de processos comuns da vida cotidiana que, quando em estado hipnótico, tornam-se mais intensos e nítidos, de maneira a serem usados pelo paciente para aliviar ou modificar algumas partes de suas dores vividas. Dito de outro modo, os esquecimentos, distrações, vivências de tempo, sensações de peso em partes do corpo, isto é, processos presentes no funcionamento psíquico cotidiano, podem favorecer a emergência de amnésias, dissociações, distorções de tempo e analgesias em estado hipnótico (Edgette \& Edgette, 1995) que, utilizados de acordo com as características particulares da experiência do paciente, favorecem alterações significativas nesse processo.

Assim, a linguagem hipnótica apresenta características muito específicas que visam evocar tais fenômenos, colocá-los perceptíveis ao paciente e situar esse paciente na condição de alguém que possa utilizar tais fenômenos a favor de suas demandas. Tal processo de indução ocorre de modo singular, uma vez que a linguagem hipnótica, longe de se constituir como uma persuasão coerente e racional, comumente se estabelece num processo de comunicação que enfatiza a forma e a redundância, além de outras maneiras de transgressão da linguagem comum (Melchior, 1998). No processo de levar alguém ao transe, o terapeuta costuma repetir as frases expressas pela pessoa, acrescentando, entre partes de suas frases, pequenas sugestões em tons de voz diferenciados, isto é, a técnica do entremeamento (Erickson, 1966). Outra transgressão típica da indução hipnótica ocorre quando o terapeuta atribuiu intencionalidade a certas partes do corpo e da mente, colocando-as como sujeitos da oração portadores de intenções, sensações e vontades independentes das deliberações conscientes da pessoa.

Nesse sentido, o sujeito da frase na sugestão hipnótica, com toda sua intencionalidade e poder de ação, parece assumir várias possibilidades distintas das noções habituais de eu, o que remete o paciente a sua própria dimensão inconsciente. Ele pode ser um braço, um órgão interno, a dor, um processo psíquico, um fenômeno hipnótico, o rio de uma metáfora narrada e ao ser apresentado ao paciente, outras formas de intencionalidade e inteligência que habitam seu inconsciente são evocadas e colocadas disponíveis para o trabalho terapêutico. Embora essa experiência possa ser marcada por uma sensação de estranheza do paciente quanto a tal processo, ele pode gradativamente se identificar com seu eu inconsciente, estabelecendo com o mesmo uma relação de diálogo e negociação que é de considerável importância para a produção dos fenômenos hipnóticos. $\mathrm{O}$ paciente pode aprender a "se deixar levar por seu inconsciente" para outro lugar deixando seu corpo com suas dores ali naquele recinto (o que consiste no fenômeno da dissociação); pode permitir que seu inconsciente faça os momentos sem dor passarem vagarosamente e de forma agradável e o tempo com dor passar de forma rápida (distorção do tempo); pode permitir que a dor seja espalhada pela água do "rio que vem de sua mente" de maneira a reduzir sua intensidade (deslocamento); pode revisar vários momentos de sua vida mostrados pelo seu inconsciente em que são enfatizadas diversas formas de conquista e superação (regressão de idade) que lhe trazem novo alento para lidar com a situação presente. Paradoxalmente, ele se apropria de sua experiência, mas sabe que não pode manuseá-la de forma deliberada e unilateral, posto que uma gama de processos não se encontra sob seu controle e depende de uma aliança com tais dimensões de seu eu inconsciente.

Esse conjunto de técnicas ligadas ao habitus na produção do fenômeno hipnótico possui uma característica importante em termos pragmáticos, uma vez que incluem no processo terapêutico, de forma nítida, o paciente atrelado a uma perspectiva de um fazer concreto. Associando-se a essa dimensão que parece distinta de si, mas com a qual passa a se relacionar - o eu inconsciente - ele se torna um pesquisador seu próprio mundo, explorando seus recursos e produzindo fenômenos que habitualmente teria dificuldades em produzir e que ainda são de grande eficácia para influenciar suas dores. Assim, ele percebe que a ação eficaz não é exclusiva do mundo externo (como as pílulas e procedimentos médicos), mas também pode ser acessada e utilizada por meio sua própria experiência da qual ele passa, gradativamente, a se apropriar. Em suma, essa dor passa por uma mudança qualitativa de grande impacto em sua subjetividade, pois de algo que simplesmente se impõe a ele, fazendo-o sofrer, ela se torna um objeto circunscrito com a qual pode interagir e, em diferentes momentos, influenciar e modificar.

\section{CONTO DE HISTÓRIAS}

A compreensão dos sentidos subjetivos constituídos pelo sujeito e das metáforas sob as quais vivencia seu cotidiano permite ao terapeuta a construção de histórias que são de grande relevância para o desencadeamento de processos terapêuticos 
junto ao paciente. O conto de histórias, acompanhadas de metáforas, analogias e paradoxos é uma inovação trazida por Erickson (Erickson \& Rossi, 1980) que rompe, em partes, com a tradição de prescrições imperativas (ou sugestões diretas) da hipnose clássica ${ }^{5}$. Tal recurso mostra-se eficaz em diversas situações clínicas de dor crônica, uma vez que não se refere a uma ordem a ser seguida de uma ou mais respostas, mas no oferecimento de toda uma estrutura (framing) de experiências e significados possíveis que podem desencadear diferentes recursos subjetivos do paciente a serem utilizados para modificar a experiência de dor que o aflige. Como ele não se vê constrangido a obedecer a uma ordem direta, ele aprecia a história e se sente convidado a participar dela em sua imaginação, uma vez que a história contada elicia espontaneamente, em seu mundo, processos já existentes que podem ser logo aproveitados como instrumentos terapêuticos de grande relevância.

Assim, ao invés de prescrever "deixe seu corpo aqui e vá para outro lugar", o terapeuta pode contar a história de alguém que "vivia uma intensa dor de cabeça, mas distraiu-se diante da TV, que seu corpo ficou ali parado e, de repente, ela deixou tudo para trás (inclusive sua dor) e viu-se num lugar muito agradável e prazeroso." Além dos fenômenos hipnóticos que tal história pode desencadear, o sujeito se vê envolvido na materialidade de sua experiência, com suas próprias lembranças do que seja um lugar prazeroso, sentindo em seu corpo as várias experiências possíveis do que seja "agradável" $e$ “prazeroso”, não por causa de uma ordem à qual deva obedecer (e talvez resistir), mas por meio de uma experiência que é sua e brota de seu mundo íntimo. A história, em toda sua riqueza metafórica (Lakoff \& Johnson, 2003), parece se dirigir a uma série de dimensões da subjetividade do paciente, ricas em potencialidades além dos pensamentos conscientes e deliberados, colocando-as em pauta num contexto relacional e otimizando suas capacidades de lidar com situações particulares de dores crônicas (Erickson \& Rossi, 1979; Neubern, 2009b).

Entretanto, para que a história seja terapêutica, ela deve ser coerente com a forma como a experiência de dor crônica está configurada, em termos de linguagem e de sentidos subjetivos, e apontar algum tipo de diretriz ou encaminhamento concreto para modificá-la. Daí a importância de que, por um lado, a história possa incluir a forma de o paciente desenvolver seu raciocínio,

5 É importante ressaltar que Erickson (Erickson \& Rossi, 1980) não aboliu a sugestão direta. Tal recurso poderia ser utilizado eventualmente, mas a ênfase do processo terapêutico deveria ser conferida às sugestões indiretas. palavras-chave por ele utilizadas, enfatizar seus sentidos físicos dominantes, sua maneira de assumir um papel nas relações pessoais, seu tom de voz, sua atribuição de causalidade para os eventos do mundo, dentre outros aspectos que configuram sua experiência (Erickson, 1983). Por outro lado, é importante que a história envolva elementos com as quais o paciente possa se identificar por meio de um enredo que mostre alguma forma de direcionamento ou superação de problemas ou obstáculos que sejam simbolicamente pertinentes com relação aos sentidos subjetivos configurados em sua dor. Comumente, esses elementos tornam-se sujeitos nas orações, como já mencionado, que diante de um obstáculo simbolicamente semelhante àquele vivido pelo paciente, descobrem ou criam novas formas de lidar com ele, percebê-lo e até superá-lo. O que se busca com essa forma de contar histórias, num contexto dramático de relação (Zeig \& Geary, 2000), não é necessariamente a produção de insights, mas o desencadeamento de processos inconscientes que possam favorecer a modificação da experiência de dor do paciente que se assume como sujeito do processo (Erickson, 1959, 1983).

Em outras palavras, não é apenas o alívio físico em si que deve ser buscado, mas uma atuação sobre os diferentes processos simbólicos e emocionais que se entrelaçam na produção de sentidos constituídos pelo sujeito em seu cotidiano e que comumente constituem o sofrimento oriundo das dores crônicas (Neubern, 2009a). Assim sendo, além das possibilidades de deslocamento das sensações de facadas de uma fibromialgia, a história terapêutica contada a uma paciente pode beneficiá-la mais a fundo caso a ajude a não mais ser explorada financeiramente na família; para outro paciente, pode contemplar a ruptura de um mecanismo antecipatório de ansiedade por meio de uma amnésia e também levá-lo a uma revisão profunda de sua história de vida, trazendo novas possibilidades de sentido sobre sua forma de lidar com as finanças; para outro ainda, enquanto o auxilia nas habilidades dissociativas, também o leva a estar mais receptivo quanto às possibilidades de repensar o tratamento de seu câncer. Uma história efetivamente terapêutica, desse modo, deve possibilitar a reconstrução simbólica de processos que se enraízam na experiência do sujeito e remetem não só a padrões de funcionamento psicofísicos específicos, mas também a uma gama considerável de emoções e sentidos subjetivos desenvolvidos em diferentes momentos de inserção social do sujeito.

\section{CONSIDERAÇÕES FINAIS}

Um dos pontos mais importantes destacados neste trabalho, que talvez sintetize sua proposta geral, é a 
importância de uma olhar clínico e qualitativo que subsidie a pesquisa de processos hipnóticos, principalmente no tocante à sua aplicação para demandas de dores crônicas. Isto porque, ao desconsiderarem esse olhar, os pesquisadores se distanciam tanto do campo que pretendem estudar, e daí o grande risco de descaracterizá-lo, como da possibilidade de diálogo com os clínicos que nele se inserem, que deveriam se tornar interlocutores valiosos para seus estudos. Assim, podem facilmente constatar que, de fato, a hipnose se constitui numa técnica eficaz para dores crônicas (Jensen \& Patterson, 2006), mas não vão muito além disso em suas conclusões, sem se interrogarem, por exemplo, como isso acontece e do que se compõe o complexo tecido relacional que se constitui na cena da ação hipnótica. O espírito científico, com todo seu poder de indagação, dúvida e questionamento, fica assim prejudicado, o que tende a contribuir para que a hipnose continue sendo vista como uma técnica eficiente, mas longe de ser explicada (Neubern, 2009c). Logo, a importância da noção de prática social (Bourdieu, 2000) aqui trazida surge como uma alternativa interessante para mapear o tecido que constitui o processo hipnótico, de maneira a apontar novas possibilidades de compreensão e pesquisa para o mesmo.

No presente estudo foi possível esboçar a importância de determinadas zonas de sentido, que compõem o processo hipnótico e são de grande valia para uma compreensão mais aprofundada e clínica do mesmo. A importância da compreensão da hipnose enquanto um processo relacional é de grande valor epistemológico e metodológico por romper com a tendência dominante de considerá-la como uma aplicação unilateral de técnicas (Neubern, 2009c), um processo no qual o terapeuta, independente de como o fizesse, aplicaria certos procedimentos cuja eficácia pareceria se impor à revelia do sujeito. O que o presente estudo buscou destacar é que a qualidade da relação e o protagonismo dos sujeitos envolvidos é fundamental para que o processo hipnótico chegue a bom termo no sentido de reconfigurar a experiência do sujeito, inclusive suas dores. Mais que isso, essa relação é perpassada por outras ordens de processos qualitativos que não podem passar desapercebidos na pesquisa, tais como os ligados aos habitus (Bourdieu, 2000) do terapeuta, com suas crenças, conceitos teóricos, uso da materialidade na relação e a dramaticidade de seus papéis. Em síntese, trata-se de uma zona de sentido que possui uma importância capital, tanto por caracterizar a hipnose como processo interativo, como por favorecer a condição de sujeito em seus participantes, o que é de fundamental valor para a modificação das experiências de dores crônicas. Desse modo, caso as pesquisas contemplem tais critérios, principalmente no que se refere à emergência da condição de sujeito e à qualidade da relação terapêutica, terão uma condição muito mais ampla de se aproximar deste campo de estudo como de aumentar seu poder explicativo sobre o mesmo.

Já as zonas de sentido referentes à fabricação do fenômeno hipnótico e ao conto de histórias possuem um apelo qualitativo de pesquisa no que se refere à dimensão técnica, principalmente no que concerne ao uso da linguagem da parte do terapeuta e da instrumentalização do paciente. Na primeira delas, há um ponto de grande importância a ser considerado, pois a produção do fenômeno hipnótico depende de uma boa percepção do terapeuta quanto aos recursos, processos e aprendizados do sujeito, uma vez que é por estes que o fenômeno é construído. Caso este ponto não seja considerado, corre-se o risco de classificar o paciente como um mal sujeito hipnótico, sem compreender suas possibilidades hipnóticas, o que acontece com certa frequência em estudos que generalizam a perspectiva de conceber o fenômeno hipnótico (Carli, Huber \& Santarcangelo, 2008). Daí a importância de que a abordagem técnica do terapeuta contemple a singularidade do sujeito de modo a estimular e promover a produção de fenômenos específicos, cujo potencial se encontra em seu repertório subjetivo (Zeig \& Geary, 2000). Torna-se, portanto, necessário que a pesquisa contemple essa condição - a do terapeuta que sabe "ler" a potencialidade hipnótica de seus pacientes já que tal habilidade se mostra como um ponto de grande importância técnica para que o processo hipnótico seja bem sucedido (Erickson, 1983).

O conto de histórias, por sua vez, implica numa produção literária sobre o paciente que envolve elementos que compreende desde a coerência linguística com suas expressões, a semelhança simbólica com seus cenários de vida e a construção de diretrizes que sejam pertinentes e possíveis para aquele sujeito particular (Zeig \& Geray, 2000). Trata-se de uma forma muito significativa de produzir sugestões, que difere largamente da forma tradicional e direta do modelo clássico, e possui uma eficácia de produção simbólica considerável, ao mesmo tempo em que envolve e convida o sujeito a uma participação ativa do processo terapêutico (Erickson, 1983; Erickson \& Rossi, 1979). Logo, essa forma de conduzir as sugestões se distancia de seu uso tradicional de prescrições diretas de maneira a trazer novas exigências e critérios de compreensão e pesquisa do processo 
hipnótico que podem abarcar a riqueza da sugestão, sua proximidade quanto à linguagem e ao mundo do sujeito e sua potencialidade em produzir soluções para os problemas por ele vividos. Semelhante perspectiva será de grande relevância em termos de pesquisa, por abrir o campo de estudos sobre o uso e a qualidade da sugestão, o que raramente ocorre nas pesquisas contemporâneas.

Por fim, cabe ressaltar que, embora a relação entre clínica e pesquisa possa encontrar saudáveis momentos de tensão, a investigação de um determinado campo, com suas diferentes zonas de sentido, deve abarcar suas características, de maneira a desenvolver seus aportes e procedimentos a partir delas. Além de ser uma forma de evitar a descaracterização do campo, é uma condição para qualificar e obedecer às exigências que este mesmo campo cria para que uma pesquisa seja realizada e mantenha uma coerência com aquilo que estuda, o que implica em duas questões básicas, intimamente ligadas. A primeira delas refere-se a uma condição de conhecer melhor o campo, evitando que suas zonas de sentido sejam diluídas pela ação imperialista de um método que se arvore o teor de científico desconsidere o campo nos processos que o constituem. Daí vem todo o esforço deste trabalho em destacar o que faz da hipnose um conjunto de processos específicos, com suas zonas de sentido ligados ao aspecto interativo da relação humana, à condição de sujeitos de seus protagonistas, a um habitus ligados a uma tradição que se faz presente de forma tão marcante na relação, na linguagem, na fabricação do fenômeno hipnótico e no conto de histórias. Em segundo lugar, considera-se que a pesquisa em campos que envolvem a subjetividade das relações humanas seja um espaço de interlocução em que o pesquisador se pergunte com quem ele dialoga; parte-se aqui do pressuposto de que o paciente é capaz de lhe fazer perguntas e críticas sobre aquilo que o pesquisador afirma ou faz quanto às práticas sociais desse campo (Nathan, 2006). Nesse sentido, o esforço de descrever e apresentar tais zonas de sentido neste trabalho também surge como possibilidade de que aqueles que se implicam com a hipnose, como terapeutas e pacientes, possam reconhecê-la quando a ela se referirem, de maneira a se posicionarem e questionarem os pesquisadores e estudiosos que tomam suas práticas sociais como objetos de pesquisa. Afinal, a hipnose que as pesquisas contemporâneas toma como objeto parece ter muito pouco a ver com as práticas sociais dessas pessoas, que talvez jamais se reconhecessem nessas pesquisas, nem legitimassem suas afirmações.

\section{REFERÊNCIAS}

Bachelard, G. (2007). L'Air et les songes. Essai sur l'imagination $d u$ mouvement. Paris: José Corti. (Original publicado em 1943).

Bourdieu, P. (2000). Esquisse d'une théorie de la pratique. Paris: Seuil. (Original publicado em 1972).

Carli, G., Huber, A., \& Santarcangelo, E. (2008). Hypnotizability and chronic pain: An ambigous connection. Contemporary Hypnosis, 25 (2), 65-77.

Csordas, T. (2002). Body/meaning/healing. New York: Palgrave Macmillan.

Edgette, J., \& Edgette, J. (1995). The handbook of hypnotic phenomena in psychotherapy. New York: Brunner \& Mazel.

Erickson, M. (1959). Hypnosis in painfull terminal illness. American Journal of Clinical Hypnosis, 1, 117-121.

Erickson, M. (1966). The interpersal hypnotic technique for symptom correction and pain control. American Journal of Clinical Hypnosis, 8, 198-02.

Erickson, M. (1983). An introduction to study and application of hypnosis in pain control. In $\mathbf{M}$. Erickson., \& Rossi, E. (Ed.) Healing in Hypnosis (pp. 217-277). New York: Irvington.

Erickson, M., \& Rossi, E. (1979). Hypnotherapy: an exploratory casebook. New York: Irvington.

Erickson, M., \& Rossi, E. (1980). The collected papers of Milton Erickson, MD. New York: Irvington.

Frankl, V. (2007). A presença ignorada de Deus. (W. Schluup, Trad.). Petrópolis: Vozes. (Original publicado em 1988).

Gonzalez Rey, F. (2005). Pesquisa qualitativa $e$ subjetividade. São Paulo: Thomsom.

Gonzalez Rey, F. (2007). Psicoterapia, subjetividade $e$ pós-modernidade. São Paulo: Thomsom.

Jensen, M., \& Patterson, D. (2006). Hypnotic treatment of chronic pain. Journal of Behavioral Medecine, 29 (1), 95-124.

Kandiba, K., \& Biniki, Y. (2003). Hypnosis as a therapy of vulvar vestibulitis syndrome: a case report. Journal of Sex and Marital Therapy, 29 (2), 237-242.

King, B., Nash, M., Spiegel, D., \& Jobson, K. (2001). Hypnosis as an intervention in pain management. A brief review. International Journal of Psychiatry and Clinical Practice, 5, 97-101.

Lakoff, G., \& Johnson, M. (2003). Metaphors we live by. Chicago: Chicago University Press.

Liossi, C. (2006). Hypnosis in cancer care. Contemporary Hypnosis, 23 (1), 47-57.

Martins, F., \& Batista, A. (2002). Atos de fala e hipnose. Psicologia em Revista, 8 (11), 92-104.

Melchior, T. (1998). Créer le Reel. Hypnose et thérapie. Paris: Seuil.

Merleau-Ponty, M. (2008). Phénoménologie de la perception. Paris: Gallimard. (Original publicado em 1945). 
Nathan, T. (2006). À qui j'appartiens? Écrits sur la psychothérapie, sur la guerre et sur la paix. Paris: Les empêcheurs/Seuil.

Neubern, M. (2009a). Hipnose e dor: proposta de metodologia clínica e qualitativa de estudo. Psico (USF), 14 (2), 201-209.

Neubern, M. (2009b). Hipnose, dor e subjetividade: considerações teóricas e clínicas. Psicologia em Estudo, 14 (2), 303-310.

Neubern, M. (2009c). Psicologia, hipnose e subjetividade. Revisitando a história. Belo Horizonte: Diamante.

Neubern, M. (2010). O terapeuta e o contrato terapêutico: em busca de possibilidades. Estudos e Pesquisas em Psicologia, 3, 882-897.

Nogueira, C., Lauretti, G., \& Costa, R. (2005). Avaliação duplamente encoberta da hipnose em fibromialgia. São Paulo Medical Journal, 14 (1),123.

Roustang, F. (2006). Savoir attendre pour que la vie change. Paris: Odile Jacob.
Stanislavski, C. (2006). A construção do personagem. (P. Lima, Trad.). Rio de Janeiro: Civilização Brasileira. (Original publicado em 1964).

Turk, D., Swanson, K., \& Tunks, E. (2008). Psychological approaches in the treatment of chronic pain patients when pills, scalpels and needles are not enough. The Canadian Journal of Psychiatry, 53 (4), 213-223.

Zeig, J., \& Geary, B. (2000). The letters of Milton Erickson. Phoenix: Tucker \& Theisen.

Recebido em 14-10-2010 Aceito em 13-08-2012
Endereço para correspondência:
Mauricio da Silva Neubern. Universidade de Brasília (UnB), Campus Universitário Darcy Ribeiro, ICC Sul, Instituto de Psicologia, Departamento de Psicologia Clínica, CEP 70910-900, Brasília-DF.E-mail:mrsouza@ufpa.br. 